CHAN-MI KIM*, PEYALA DHARMAIAH*, HYO-SEOB KIM*, JAR-MYUNG KOO*, JAE-SIK YOON**, HYUN-SEON HONG***, SOON-JIK HONG*\#

\title{
EFFECT OF ACID DISSOLUTION CONDITIONS ON RECOVERY OF VALUABLE METALS FROM USED PLASMA DISPLAY PANEL SCRAP
}

\begin{abstract}
The objective of this particular study was to recover valuable metals from waste plasma display panels using high energy ball milling with subsequent acid dissolution. Dissolution of milled (PDP) powder was studied in $\mathrm{HCl}, \mathrm{HNO}_{3}$, and $\mathrm{H}_{2} \mathrm{SO}_{4}$ acidic solutions. The effects of dissolution acid, temperature, time, and PDP scrap powder to acid ratio on the leaching process were investigated and the most favorable conditions were found: (1) valuable metals ( $\mathrm{In}, \mathrm{Ag}, \mathrm{Mg}$ ) were recovered from PDP powder in a mixture of concentrated hydrochloric acid $\left(\mathrm{HCl}: \mathrm{H}_{2} \mathrm{O}=50: 50\right) ;(2)$ the optimal dissolution temperature and time for the valuable metals were found to be $60^{\circ} \mathrm{C}$ and $30 \mathrm{~min}$, respectively; (3) the ideal PDP scrap powder to acid solution ratio was found to be 1:10. The proposed method was applied to the recovery of magnesium, silver, and indium with satisfactory results.
\end{abstract}

Keywords: High energy ball milling, waste plasma display panels, dissolution, recovery

\section{Introduction}

After the entry into the $21^{\text {st }}$ century, the rapid development of technology has led to many new electronic products. As a result, old products are being replaced by newer models at a faster rate, e.g., the continuous replacement of CRT monitors by LCD displays and/or plasma monitors and the recent introduction of high definition TV sets. Predictions indicate that large numbers of televisions will need to be disposed of in the coming days [1]. Plasma display panels (PDPs) are made with glass substrate, gas mixtures, phosphor materials, barriers, black matrix, dielectric layers, $\mathrm{MgO}$ protective layer, and transparent electrodes [2]. The emerging problem of e-waste from plasma panels is thought to be creating an environmental problem due to massive disposal of such panels. PDPs utilize indium in the form of indium-tin oxide (ITO) as an electrode material. This material is extensively used to fabricate additional optoelectronic devices, such as liquid-crystal display panels, solar panels, and organic light-emitting diodes as transparent electrodes [3-5]. In recent years, there has been a tremendous increase in the production and sale of electronic devices, resulting in a rapid increase in the demand for indium, magnesium and silver. Display panels contain one or more printed circuit boards that are equipped with electronic components and connectors. Important amounts of precious metals like silver $(\mathrm{Ag})$, and gold $(\mathrm{Au})$ are contained in the components and connectors, as well as in the solder [6].
Further, many hazardous substances used in PDPs, such as lead, mercury, etc., can have significant adverse impacts on human health and the environment if improperly disposed of [7-9]. Due to the scarcity of indium, magnesium, and silver, and growing popularity of plasma TVs and monitors, the recovery of valuable metals (In, Mg, Ag) from secondary sources has been receiving more and more attention.

Extraction with solvents is a commonly used method for the recovery of valuable metals from e-waste; several extractant types have been found, including carboxylic acids, di-2-ethylhexyphosphoric acid, and chelating compounds [10]. Earlier than the year 2000, researchers used traditional methods, which mainly focused on the safe disposal of hazardous materials for scrap e-waste; they were not concerned with the recovery of resources. Since 2000, researchers have been trying to develop various technologies to recover valuable materials [11-12]. Numerous investigators have studied methods to recover valuable metals from solutions using chemical precipitation followed by solvent extraction [13-15]; some others have attempted to separate indium from other waste by adjusting the $\mathrm{pH}$ value of the solution. However, due to the recovery ratio, these traditional approaches have disadvantages when the concentration of precious metals is low in solution; and high energy requirements. The acid leaching process normally requires a small grain size to increase the metal yield. In general, researchers have used conventional shredding machines to crush the used e-waste and

\footnotetext{
* DIVISION OF ADVANCED MATERIALS ENGINEERING AND INSTITUTE FOR RARE METALS, KONGJU NATIONAL UNIVERSITY, CHEONAN 331-717, REPUBLIC OF KOREA

** KOREA BASIC SCIENCE INSTITUTE, DAEJEON CITY, REPUBLIC OF KOREA.

*** DEPARTMENT OF INTERDISCIPLINARY ECO SCIENCE, SUNGSHIN UNIVERSITY, SEOUL, KOREA

\# Corresponding author: hongsj@kongju.ac.kr
} 
have obtained particle sizes in the millimeter scale, which leads to recovery processes that take a long time. The high energy ball milling (HEBM) system is an attractive and efficient alternative method to produce particles on the micrometer/nanometer scale in a very short period. For that reason, we have used a high energy ball milling system (HEBM) in this study. In earlier works, the recovery of indium from aqueous solutions using different acidic, solvating, and chelating extractants was performed. These studies showed that the acidic extractants are the most effective choice for recovery of precious metals from acidic solutions and the separation of those metals from the electronic waste $[11,16]$.

In the present study, the potential recovery of valuable metals from crushed plasma display panel glass using high energy ball milling and acid leaching has been investigated. The leaching of indium, magnesium, and silver in $\mathrm{HCl}, \mathrm{HNO}_{3}$, and $\mathrm{H}_{2} \mathrm{SO}_{4}$ was studied. Besides this, we tried to optimize the acid solution and to determine the effects of the dissolution temperature and time on the $\mathrm{HCl}$ solution. The dissolution of valuable metals as a function of the ratio of the PDP powders to the $\mathrm{HCl}$ acid solution was studied.

\section{Experimental process}

Schematic structure of the PDP electrode is shown in Fig. 1a. The plasma display panel consists of a dielectric glass substrate, an $\mathrm{MgO}$ layer, and a back light module. The surface of the dielectric layer was attached with polarizing film; the inner side was coated with functional films, called the indium-tin oxide (ITO) electrode. The PDP structure was complex; it was difficult to effect the separation of the electrodes. Initially, plasma display panels are manually smashed with a tack hammer to acquire cullets. The cullets were irregular in shape and of non-uniform sizes of around $3 \mathrm{~mm}$ in thickness and $5 \mathrm{~mm}$ in diameter, and SEM image of the PDP powder are shown in Fig. 1b,c.

Next, the cullet was cleaned with alcohol to reduce impurities. Cullets containing valuable metals were milled to obtain micron size particles using a High Energy Ball Mill machine (Planetary Mill P100) with a jar and balls made of $\mathrm{ZrO}_{2}$ in $\mathrm{Ar}$ atmosphere at optimized milling time. From our previous studies on the effects of milling conditions on the dissolution efficiency of valuable metals, we were able to know that 3 min milling time was the optimum choice [17]. The average ball size was around $5 \mathrm{~mm}$ in diameter. Ball to PDP scrap ratio was 10:1 and $1100 \mathrm{rpm}$ rotational speed was applied. The powder morphology was examined using scanning electron microscopy (SEM-MIRA LMH II (TESKAN), USA). The whole process designed for the recovery of valuable materials from plasma display panels is illustrated in Fig. 2. HEBMed micron size powder were immersed in an acid solution and stirred at $900 \mathrm{rpm}$ using a laboratorystirring machine (TopeMS3040 Lab.Stirrer) until a transparent solution was obtained. Purities of the acids $\mathrm{H}_{2} \mathrm{SO}_{4}, \mathrm{HNO}_{3}$, and $\mathrm{HCl}$ used in this study were 66,46 , and $36 \%$, respectively. In this experiment, acid: $\mathrm{H}_{2} \mathrm{O}=50: 50\left(\right.$ acid $\left.=\mathrm{HCl}, \mathrm{H}_{2} \mathrm{SO}_{4}, \mathrm{HNO}_{3}\right)$ was used as acid solution after milling. Chemical analysis to
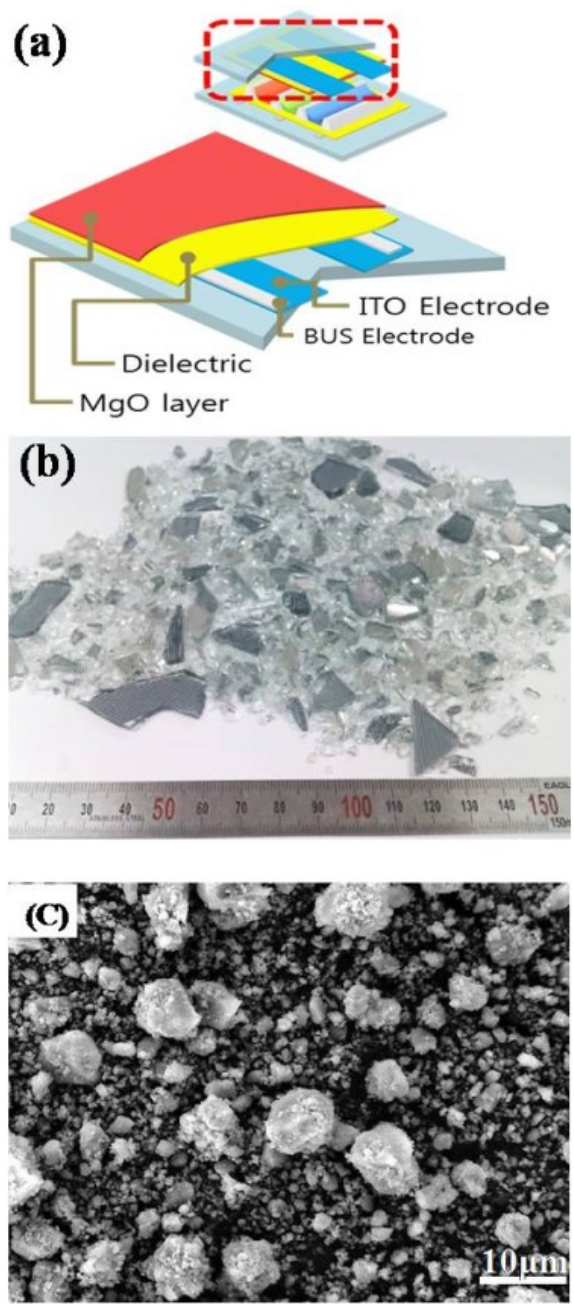

Fig. 1. (a) Schematic structure of Plasma Display Panel (PDP) electrode, (b) Photo of waste PDP panel cullet, and (c) SEM image of PDP powders produced by high energy ball milling at $1100 \mathrm{rpm}$

determine the indium, silver, and magnesium content in the acid solution was carried out using an inductively coupled plasma mass spectrometer (ICP-MS).

\section{Results and discussion}

The technology for the recovery of indium, silver, and magnesium from acid solutions has been wisely applied in the industry; however, the successful dissolution of valuable metals from PDPs is still dependent on advanced techniques. The parameters that impact the dissolving efficiency include the particle size of the crushed panels, the acids used, and the dissolution temperature and time. Particle size is known to strongly depend on the milling time; the dissolving efficiency of the valuable metals depends on the particle size [11]. An SEM image of the PDP powder is shown in Fig. 1c. The average particle size of the milled PDP powder was less than $10 \mu \mathrm{m}$; powder particles appear to have round shapes. The surface area of the solid increased due to the creation of fine particles during milling and the ease of the chemical induced interactions among the surface components 


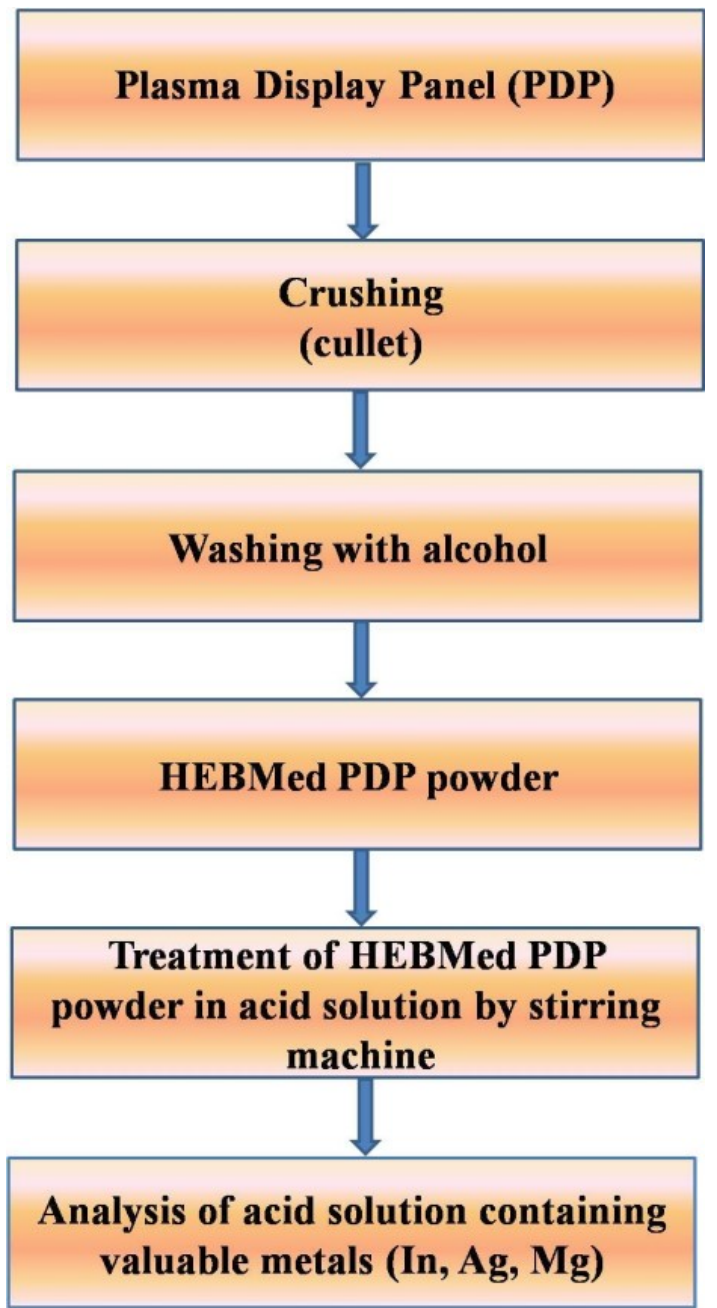

Fig. 2. Whole process designed for the recovery of valuable materials from plasma display panels

[12]. A comparison of the dissolution amount of valuable metals in different acid solutions $\left(\mathrm{H}_{2} \mathrm{SO}_{4}, \mathrm{HNO}_{3}\right.$, and $\left.\mathrm{HCl}\right)$ is shown in Fig. 3. The number of ITO and MgO layers in PDP glass can also vary between different manufacturers and models; also, plasma display panel glass can be mixed with other parts of the display. Furthermore, loss of materials can take place during the shredding and other processes, resulting in lower indium and silver concentrations. The results show that indium, magnesium, and silver have different levels of solubility in different acid solutions [16]. The main reactions of $\operatorname{In}_{2} \mathrm{O}_{3}, \mathrm{Ag}_{2} \mathrm{O}$, and $\mathrm{MgO}$ with acids are as follows $[4,15,18]$.

$$
\begin{aligned}
& \mathrm{In}_{2} \mathrm{O}_{2}+6 \mathrm{~h}^{+} \rightarrow 2 \mathrm{In}^{+++}+3 \mathrm{H}_{2} \mathrm{O} \\
& \mathrm{MgO}_{(\mathrm{s})}+2 \mathrm{HCl}_{(\mathrm{aq})} \rightarrow \mathrm{Mg}^{2+}{ }_{(\mathrm{aq})}+2 \mathrm{Cl}^{-}{ }_{(\mathrm{aq})}+\mathrm{H}_{2} \mathrm{O}_{(\mathrm{l})} \\
& \mathrm{AgCl}_{(\mathrm{s})} \rightarrow \mathrm{Ag}^{+}{ }_{(\mathrm{aq})}+\mathrm{Cl}^{-}{ }_{(\mathrm{aq})}
\end{aligned}
$$

The dissolution value of magnesium is $140 \mathrm{mg} / \mathrm{L}$ in $\mathrm{H}_{2} \mathrm{SO}_{4}$ acid solution. This is a high value compared to the dissolution value of $\mathrm{Mg}$ in $\mathrm{HNO}_{3}$ and $\mathrm{HCl}$ acid solutions. Compared to that of silver, the indium dissolution value is very low in $\mathrm{H}_{2} \mathrm{SO}_{4}$ acid dissolution. The dissolution values of silver and indium are higher in $\mathrm{HCl}$ acid solution than that in $\mathrm{H}_{2} \mathrm{SO}_{4}$; the use of
$\mathrm{HNO}_{3}$ resulted in considerable increases in the rate of dissolution. A very good recovery of these valuable metals ( $\mathrm{In}, \mathrm{Ag}, \mathrm{Mg}$ ) in chloride media was achieved. The chloride medium produced more stable soluble metals than did the sulfate medium. The dissolution values of indium and silver in $\mathrm{HCl}$ solution are good and comparable to those in $\mathrm{H}_{2} \mathrm{SO}_{4}$ and $\mathrm{HNO}_{3}$ solutions.

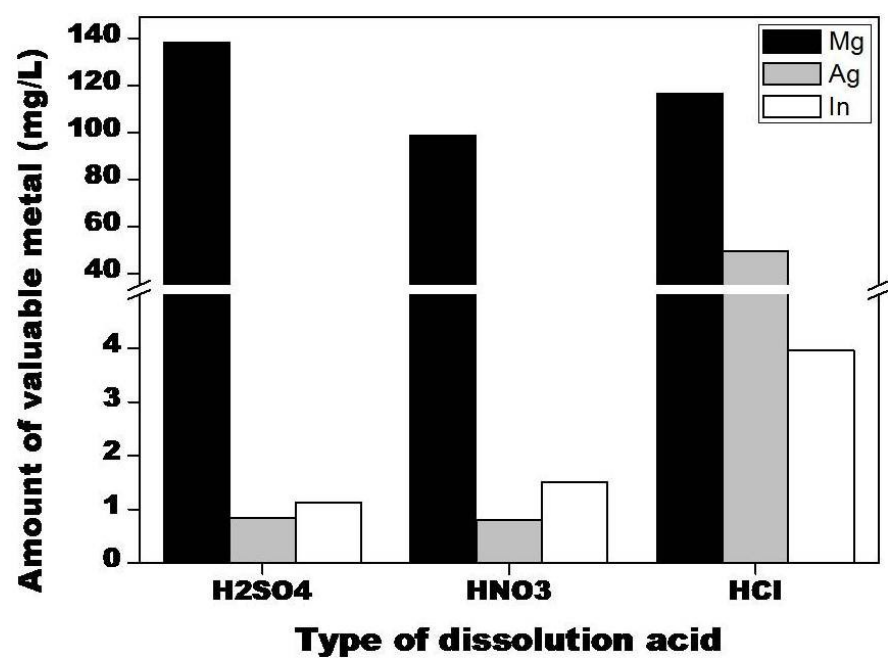

Fig. 3. Comparison of dissolution amount of valuable metals with different acid solutions

Based on the results, the dissolution values of valuable metals ( $\mathrm{In}, \mathrm{Ag}, \mathrm{Mg}$ ) in $\mathrm{HCl}$ acid solution strongly recommends the use of this acid for a more effective recovery of indium and silver from plasma display panels (PDP). The $\mathrm{H}_{2} \mathrm{SO}_{4}$ media are very weak at recovering indium and silver. However, $\mathrm{H}_{2} \mathrm{SO}_{4}$ is less corrosive for the process equipment than is $\mathrm{HCl}$, and this presents a slight advantage [16]. The results show magnesium has a somewhat similar dissolution value in these acid solutions. Some other researchers have reported that the combination of a strong acid and a strong oxidative acid, such as the mixture of $\mathrm{HNO}_{3}$ and $\mathrm{HCl}$ acid solutions, could be helpful to speed up the indium dissolution [19]. However, $\mathrm{HNO}_{3}$ is more expensive than $\mathrm{HCl}$. Hence, the usage of $\mathrm{HNO}_{3}$ increases the cost. In our case, with the help of HEBM, it was easily possible to get micron size particles within a short period of time. As the particle size decreases, an effective surface of the acid solution and a high dissolution value were obtained. Therefore, $\mathrm{HCl}$ acid solution is more efficient for the recovery of indium, silver, and magnesium. We continued experiments to optimize the effect of the dissolution temperature for the recovery of valuable metals.

Fig. 4 shows the changes in the dissolution amounts of valuable metals as a function of dissolution temperature in $\mathrm{HCl}$ acid solution. The dissolution value increased gradually as the temperature $\left(20^{\circ} \mathrm{C}\right.$ to $\left.60^{\circ} \mathrm{C}\right)$ rose. Dissolved amount of magnesium is leached preferentially at lower temperatures as well as at higher temperatures compared to the dissolution amounts of silver and indium. The silver dissolution value is high compared to that of indium. The indium dissolution value is very low at lower temperatures; it increases gradually with temperature in $\mathrm{HCl}$ acid solution. 


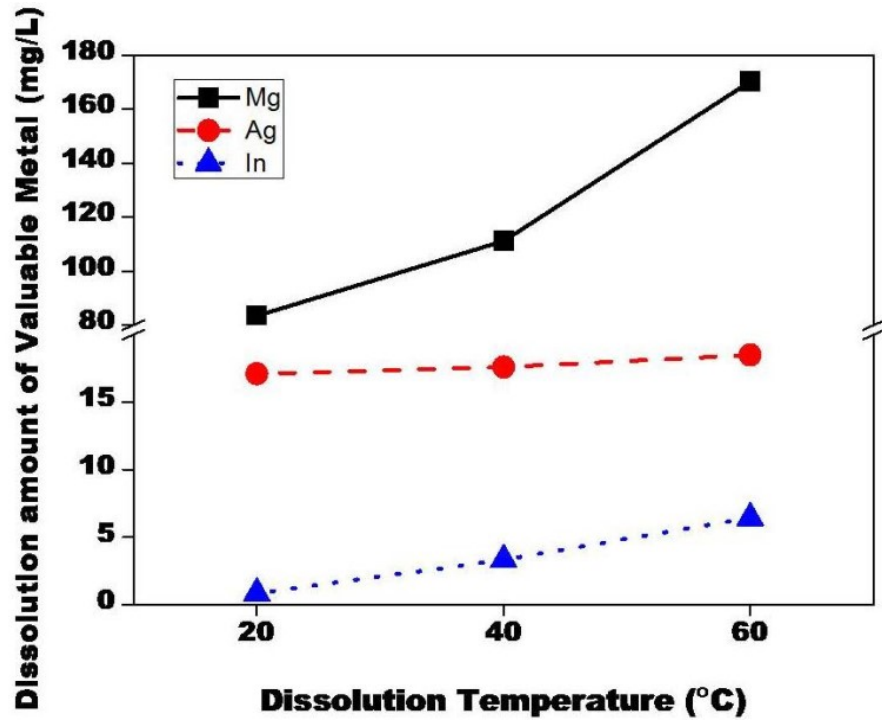

Fig. 4. Dissolution of valuable metals as a function of dissolution temperature in $\mathrm{HCl}$ acid solution $\left(\mathrm{HCl}: \mathrm{H}_{2} \mathrm{O}=50: 50\right)$ for 30 min dissolution time

According to these results, the dissolution value increases as the reaction temperature increases due to the increase in the solubility of In, $\mathrm{Mg}$, and $\mathrm{Ag}$ with increasing temperature. This is in good accord with results from previous studies in the literature, in which the reaction temperature was found to have a noticeable effect on the dissolution of metals [11]. A further improvement in the dissolution value was expected under high temperature condition. However, the dissolution value of valuable metals is high at $60^{\circ} \mathrm{C}$; beyond that temperature the solution releases toxic and irritating fumes that may have adverse impacts on human health and on the environment. Due to this fact, we considered that the $60^{\circ} \mathrm{C}$ dissolution temperature could be a proper temperature for the dissolving of indium, silver, and magnesium from plasma display panels.

Fig. 5 shows the changes in the dissolution amounts of valuable metals as a function of dissolution time in acid solution

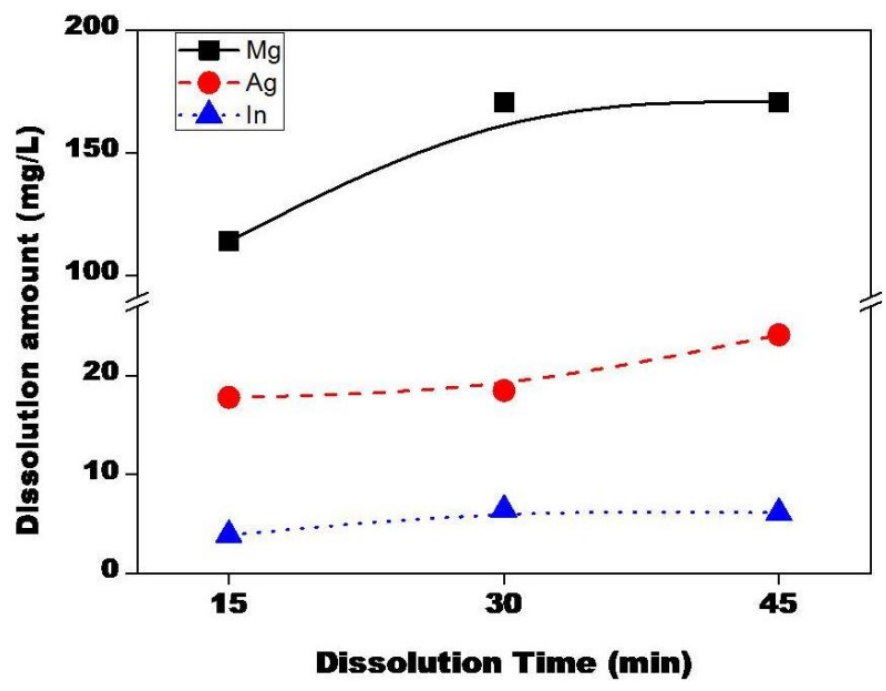

Fig. 5. Dissolution of valuable metals as a function of dissolution time in $\mathrm{HCl}$ acid solution $\left(\mathrm{HCl}: \mathrm{H}_{2} \mathrm{O}=50: 50\right)$ at room temperature
$\left(\mathrm{HCl}: \mathrm{H}_{2} \mathrm{O}=50: 50\right)$ at room temperature (RT). It is well known that the yield of metallic elements depends on the leaching time [20]. It can be easily noticed that the amounts of dissolved magnesium, silver, and indium increase gradually with respect to time in the $\mathrm{HCl}$ acid solution.

The dissolution values of indium, silver, and magnesium were $4 \mathrm{mg} / \mathrm{L}, 18 \mathrm{mg} / \mathrm{L}$, and $114 \mathrm{mg} / \mathrm{L}$ at $15 \mathrm{~min}$; these values were $6 \mathrm{mg} / \mathrm{L}, 24 \mathrm{mg} / \mathrm{L}$, and $171 \mathrm{mg} / \mathrm{L}$ at $45 \mathrm{~min}$ dissolution time, which values demonstrate increases of about $60 \%, 40 \%$, and $50 \%$ respectively. It can be observed that there was no significant change in the amounts of dissolved indium and magnesium in the acid solution $\left(\mathrm{HCl}: \mathrm{H}_{2} \mathrm{O}=50: 50\right)$ from 30 to $45 \mathrm{~min}$ dissolution time. According to these results, it can be expected that equilibrium was achieved beyond $30 \mathrm{~min}$. Therefore, a dissolution time of $30 \mathrm{~min}$ was regarded as an appropriate time in the hydrochloric acid solution $\left(\mathrm{HCl}: \mathrm{H}_{2} \mathrm{O}=50: 50\right)$. Next, we tried to optimize the PDP powder to acid ratio in order to extract a higher amount of valuable metals. Figure 6 shows the changes in the amounts of dissolved metals according to the ratio of the PDP

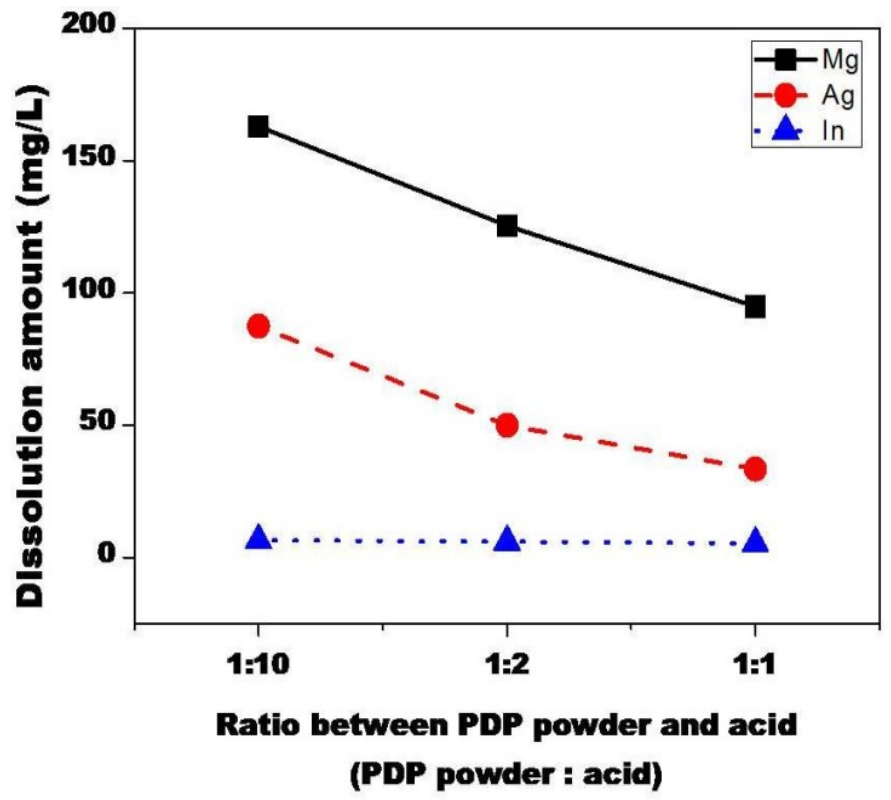

Fig. 6. Changes in amount of dissolved metals with ratio of PDP powder and acid solution $\left(\mathrm{HCl}: \mathrm{H}_{2} \mathrm{O}=50: 50\right)$ for $30 \mathrm{~min}$ at room temperature

powder to the acid solution $\left(\mathrm{HCl}: \mathrm{H}_{2} \mathrm{O}=50: 50\right)$ for $30 \mathrm{~min}$ at RT. It can be clearly observed that with a decreasing amount of acid solution and a constant amount of PDP powder, the dissolution amounts of magnesium (Mg), silver ( $\mathrm{Ag}$ ), and indium (In) remarkably decrease. When there is a 1:1 ratio of PDP powder to acid solution $\left(\mathrm{HCl}: \mathrm{H}_{2} \mathrm{O}=50: 50\right)$, the dissolution values of the metals (In, Ag, Mg) are nearly $5 \mathrm{mg} / \mathrm{L}, 33 \mathrm{mg} / \mathrm{L}$, and $94 \mathrm{mg} / \mathrm{L}$ respectively; with a 1:10 ratio of the PDP powder to the acid solution, the dissolution values of indium, silver, and magnesium are $7 \mathrm{mg} / \mathrm{L}, 87 \mathrm{mg} / \mathrm{L}$, and $163 \mathrm{mg} / \mathrm{L}$, which represent increases of about $40 \%, 160 \%$, and $80 \%$, respectively. The increases in dissolution percentages of silver and magnesium were better compared to those of indium for the 1:10 ratio of PDP powder 
to acid solution. From these results, the magnesium dissolution value can be seen to be high compared to that determined in other reported papers [18]. This discrepancy may be due to the fact that a relatively higher liquid ratio may provide a medium of liquid phase to facilitate the mobility of reactive species produced in the reaction medium. Therefore, it is possible to increase the dissolution amount of valuable metals by increasing the amount of acid solution, while the PDP powder is kept constant [21]. This might be explained by the fact that the amount of reagent was sufficient to leach indium, silver, and magnesium from PDP when the PDP powder to acid ratio was 1:10.

\section{Conclusions}

Valuable metal (In, $\mathrm{Ag}, \mathrm{Mg}$ ) recovery from plasma display panel scrap in different acid solutions $\left(\mathrm{H}_{2} \mathrm{SO}_{4}, \mathrm{HNO}_{3}, \mathrm{HCl}\right)$ was studied and $\mathrm{HCl}$ acid solution was found to be most convenient. Extracting valuable metals in acid solution $\left(\mathrm{HCl}: \mathrm{H}_{2} \mathrm{O}=50: 50\right)$ was performed under different conditions of dissolution temperature, dissolution time, and ratio of PDP powder to acid. The major conclusions derived from the present work were as follows. The dissolution rate increased with increasing temperature. The maximum dissolution amount of valuable metals was obtained at $60^{\circ} \mathrm{C}$ dissolution temperature and dissolution time of $30 \mathrm{~min}$. The maximum dissolution amount of valuable metals was obtained using a 1:10 PDP powder to acid ratio. With a decreasing amount of acid solution and a constant amount of PDP powder, the dissolution amounts of magnesium (Mg), silver (Ag), and indium (In) remarkably decrease. The increase in dissolution percentages of indium, silver, and magnesium were $40 \%, 160 \%$, and $80 \%$ respectively, obtained in acid solution $\left(\mathrm{HCl}: \mathrm{H}_{2} \mathrm{O}=50: 50\right)$.

\section{Acknowledgements}

The present research was supported by the R\&D Center for Valuable Recycling (Global-Top Environmental Technology Development Program), funded by the Ministry of Environment (Project No: 11-A02-MD)

\section{REFERENCES}

[1] C.S. Poon, Waste Manage. 28, 1499 (2008).

[2] R.M. Caloi, C. Carretti, J. Vac. Sci. Technol. A. 16, 1991 (1998).

[3] Y.H. Tak, K.B. Kim, H.G. Park, K.H. Lee, J.R. Lee, Thin Solid Films 411, 12 (2002).

[4] Y.H. Li, Z.H. Liu, Q.H. Li, Z.Y. Liu, L. Zeng, Hydrometallurgy 105, 207 (2011).

[5] H. Boni, R. Widmer, Disposal of flat panel display monitors in Switzerland Final Report, CH-9014, Gallen (2011).

[6] M. Buchert, A. Manhart, D. Bleher, D. Ping, Recycling critical raw materials from waste electronic equipment, Darmstadt (2012).

[7] B.A. Mukherjee, R. Zevenhoven, J. Brodersen, Resour. Conserv. Recy. 42, 155 (2004).

[8] F.C. Marcelo, T. Sandra, M.S. John, L.L. Silveira, V.F. Dora, Environ. Res. 107, 132 (2008).

[9] J. Li, B. Tian, T. Liu, H. Liu, X. Wen, S. Honda, J. Mater. Cycles Waste Manag. 8, 13 (2006).

[10] H. Hasegawa, I.M.M. Rahman, Y. Egawa, H. Sawai, Z.A. Begum, T. Maki, S. Mizutani, Microchem. J. 106, 289 (2013).

[11] J. Li, S. Gao, H. Duan, L. Liu, Waste Manage. 29, 2033 (2009).

[12 M.S. Steiner, Possible ways for the separation of backlight lamps, ReLCD-Workshop, March 07, Vienna, Austria 2006.

[13] B. Raju, J. Rajesh Kumar, J.Y. Lee, H.S. Kwon, M.L. Kantam, B.R. Reddy, J. Hazard. Mater. 227, 142 (2012).

[14] J. Yang, T. Retegen, C. Ekberg, Hydrometallurgy 137, 68 (2013).

[15] S. Aktas, Hydrometallurgy 104, 106 (2010).

[16] S. Virolainen, D. Ibana, E. Paatero, Hydrometallurgy 107, 56 (2011).

[17] H.S. Kim, C.M. Kim, C.H. Lee, S.K. Lee, H.S. Hong, J.M. Koo, S.J. Hong, J. Kor. Powd. Met. Inst. 20, 2 (2013).

[18] A. Fedorockova, M. Hreus, P. Raschman, G. Sucik, Miner. Eng. 32, 1 (2012).

[19] H. Takamichi, M. Toshiaki, J. Sharp Technical 92, 17 (2005).

[20] Q. Zang, K. Sugiyama, F. Saito, Hydrometallurgy. 45, 323 (1997).

[21] C.H. Lee, M. Kyung, M.F. Kilicaslan, J.H. Lee, H.S. Hong, S.J. Hong, Waste Manage. 33, 730 (2013). 